\title{
Low adiponectin is associated with diastolic dysfunction in women: a cross-sectional study from the Tromsø Study
}

Jon V. Norvik ${ }^{1,6^{*}}$ D, Henrik Schirmer ${ }^{3,7}$, Kirsti Ytrehus ${ }^{1,6}$, Trond G. Jenssen ${ }^{1,4}$, Svetlana N. Zykova ${ }^{1}$, Anne E. Eggen ${ }^{5}$, Bjørn O. Eriksen ${ }^{1,2}$ and Marit D. Solbu ${ }^{1,2}$

\begin{abstract}
Background: Heart failure with preserved ejection fraction is closely associated with diastolic dysfunction and related to obesity and female sex. We investigated whether adiponectin, an adipocyte-secreted protein hormone with cardioprotective effects, was associated with indices of diastolic dysfunction, and whether the association was sex dependent.
\end{abstract}

Methods: We conducted a cross-sectional study on 1165 women and 896 men without diabetes. We stratified the multivariable adjusted logistic regression analyses and the fractional polynomial regression analyses according to sex, with echocardiographic markers of diastolic dysfunction as dependent variables, and adiponectin as the independent variable of interest.

Results: Decreased adiponectin was associated with higher odds of average tissue Doppler $\mathrm{e}^{\prime}<9$ in women (odds ratio [OR] 1.17 per $1 \mu \mathrm{g} / \mathrm{mL}$ adiponectin decrease, 95\% confidence interval [CI] 1.04-1.30), but not in men ( $p$ for interaction with sex 0.04$)$. Women, but not men, had higher odds of E/e' ratio $\geq 8$ with lower adiponectin (OR $1.12 \mathrm{per} 1 \mu \mathrm{g} / \mathrm{mL}$ adiponectin decrease, $95 \% \mathrm{Cl} 1.02-1.24$, p for interaction with sex 0.04 ). Adiponectin in the lower sex-specific tertile was associated with increased odds of concentric left ventricular hypertrophy in women (OR 2.44, 95\% Cl 1.03-5.77), but with decreased odds in men (OR 0.32, 95\% Cl 0.11-0.88, p for interaction with sex 0.002), and decreased odds of eccentric hypertrophy in men only (OR $0.53,95 \% \mathrm{Cl} 0.33-0.88$, p for interaction with sex 0.02$)$. Adiponectin in the lower sex-specific tertile was associated with moderately enlarged left atria in women only (OR 1.43,95\% Cl 1.01-2.03, p for interaction with sex 0.04). Finally, adiponectin had a non-linear relationship with left ventricular mass in women only, with exponentially increasing left ventricular mass with lower adiponectin levels ( $p$ for interaction with sex 0.01 ).

Conclusions: Low adiponectin was associated with higher odds of indices of diastolic dysfunction in women, but lower odds of indices of diastolic dysfunction in men. Lower adiponectin was associated with increased left ventricular mass in women only.

Keywords: Diastolic dysfunction, Heart failure, HFpEF, Cardiovascular disease, Cardiac remodeling, Adiponectin, Women, Cross-sectional, Epidemiology

\footnotetext{
* Correspondence: jno031@post.uit.no

${ }^{1}$ Metabolic and Renal Research Group, UiT The Arctic University of Norway,

N-9037 Tromsø, Norway

${ }^{6}$ Cardiovascular Research Group IMB, UiT The Arctic University of Norway,

N-9037 Tromsø, Norway

Full list of author information is available at the end of the article
} 


\section{Background}

Diastolic dysfunction (DD) is a condition characterized by abnormal cardiac relaxation, stiffness or filling. Heart failure (HF) with preserved ejection fraction (HFpEF) is a clinical syndrome with symptoms and signs of HF, but with normal or only mildly reduced ejection fraction, and is closely associated with DD [1]. In developed countries, the prevalence of HF is about $1-2 \%$ of the adult population, and $\geq 10 \%$ among persons $>70$ years of age [1]. About half of HF patients have HFpEF [2]. The EURObservational Research Program: the Heart Failure Pilot Survey (ESC_HF Pilot) conducted a prospective 1 -year survey among 136 cardiology centers in 12 countries with over 5.000 HF patients enrolled [3]. The all-cause mortality rate after 1 year was $13.4 \%$ in acute HFpEF and 5.9\% in chronic, stable HFpEF. DD in itself, not accompanied by HF, is associated with increased all-cause mortality, and it is often asymptomatic [4]. Despite HFpEF being a major and growing health problem in the USA and Europe, the understanding of this condition is still scarce and there is no medical treatment of proven benefit for HFpEF [5]. In particular, HFpEF is associated with female sex, increasing age and obesity [1]. The reasons for the female preponderance for HFpEF remain unsolved [6]. It is therefore of interest to examine features associated with $\mathrm{DD}$, among them metabolic risk factors, for better understanding of possible sex-specific mechanisms leading to HFpEF.

Adipose tissue is an endocrine organ that produces a range of biologically active substances, such as the adipokines. They constitute a group of protein hormones with functions in the regulation of energy metabolism, insulin sensitivity, inflammation, atherosclerosis and cell proliferation [7]. Biologically important members include, among others, tumor necrosis factor- $\alpha$, interleukin-6, interleukin-10, omentin, leptin and adiponectin [8]. The latter is abundantly produced and secreted by adipose tissue, and during the previous decade adiponectin has been shown to have antidiabetic, antiinflammatory, anti-atherogenic and cardioprotective effects [7]. Low levels of adiponectin are in longitudinal studies associated with the development of insulin resistance [9] and hypertension [10], and adiponectin is negatively associated with body mass index (BMI) and bodyfat [11]. Reduced plasma adiponectin is associated with the metabolic syndrome [12] and higher risk of myocardial infarction [13], although, paradoxically, in chronic HF adiponectin levels tend to be high, and increasing with disease severity [14]. It has been postulated that uric acid can affect adipocytes by inducing downregulation of adiponectin [15]. Thus, there may be a biologically relevant interplay between uric acid and adiponectin.

The relationship between adiponectin and DD has not been thoroughly investigated. Since there is a female preponderance for $\mathrm{HFpEF}$, it is of relevance to assess whether these associations may differ by sex. Therefore, we wanted to do cross-sectional analyses and examine the associations between adiponectin and echocardiographic indices of DD in a large cohort of men and women from the general, non-diabetic population.

\section{Methods \\ Study population}

The Tromsø Study is a population-based, prospective study of various health issues and chronic diseases. It consists of seven surveys referred to as Tromsø 1-7, which have been conducted in the municipality of Tromsø, Norway, from 1974 to 2016 [16]. The population of the present study is the participants of the sixth wave of the Tromsø Study, conducted in 2007-2008 [17]. A total of 12,984 subjects ( 6930 women and 6054 men, $65.7 \%$ of the invited population) took part in the survey. All individuals who had attended the extended study of the fourth wave of the Tromsø Study, and were aged 50-62 years or 75-84 years plus a $20 \%$ random sample of persons aged 63-74 years (a total of 7206 subjects) were invited to an extended examination. Of these, 2243 persons were randomly selected for echocardiography. We excluded the subjects with prevalent diabetes at baseline $(n=182$; defined as HbA1c $\geq$ $6.5 \%$, non-fasting glucose $\geq 10.0 \mathrm{mmol} / \mathrm{L}$, under antidiabetic treatment or self-reported diabetes). This left 2061 subjects in the final cohort.

\section{Measurements}

The subjects completed a questionnaire, which provided information on physical activity, prevalent diabetes, smoking habits and use of medication, as previously described [16, 17]. Use of blood pressure lowering drugs was assessed through self-report (questionnaire) based on the question "Do you use, or have you used blood pressure lowering drugs? Currently/Previously but not now/Never used". Participants also reported drugs used on a regular basis the preceding four weeks; this was coded according to the Anatomical Therapeutic Chemical (ATC) classification system version 2007 (http://www.whocc.no/). We classified smoking habits as current smokers and non-smokers, and physical activity as active ( $\geq 1 \mathrm{~h}$ physical activity with prominent perspiration or breathlessness per week) or inactive (all others). We calculated BMI as weight $(\mathrm{kg}) /$ height $(\mathrm{m})^{2}$. Blood pressure was recorded after a two minutes rest in 1minute interval triplicate by an automated device (Dinamap ProCare Monitor 300, GE Healthcare, Norway). We used the mean of the second and the third measurement. Blood samples were non-fasting. Total adiponectin was analyzed by an ELISA method (DY1065 kit from R\&D Systems, Inc., Minneapolis, MN) in serum that had been stored at $-70^{\circ}$. Uric acid, serum total cholesterol, cystatin $\mathrm{C}$, triglycerides, 
$\mathrm{HbA1c}$ and serum creatinine were analyzed as previously described [17, 18]. Urine was collected and analyzed as previously described [18], and the median value of three albumin-creatinine ratio values was used, calculated from urine albumin and creatinine of first-void morning urine samples taken on three consecutive days. We calculated the estimated glomerular filtration rate (eGFR) according to the CKD-EPI creatinine-cystatin C equation [19].

\section{Echocardiography}

Transthoracic Echocardiography was performed with an Acuson Sequoia C512 Ultrasound System (Siemens Medical Solutions. Mountain View, California, USA) with a combined $3.5 \mathrm{MHz}$ second harmonic ultrasound and 2.5 MHz Doppler probe. M-mode, 2D and Doppler echocardiographic recordings were obtained and analyzed for all participants. A sonographer was the primary performer of the echocardiography examinations, with an experienced cardiologist as backup and supervisor. Measurements were done online by the sonographer as the recording was done. The measurements were also done online for the intraobserver and interobserver study where the reproducibility of measurements was assessed by new recordings as basis for comparison. Mean intraobserver variability \pm standard deviation (SD) for the sonographer for E/A ratio was $0.007 \pm 0.28$, for left atrial (LA) diameter $0.01 \pm 0.49 \mathrm{~cm}$, and for E-wave deceleration time (EDT) $6 \pm 53 \mathrm{~ms}$. The mean interobserver variability $\pm \mathrm{SD}$ between the sonographer and the cardiologist was $0.015 \pm 0.29$ for E/A ratio, $0.04 \pm 0.38 \mathrm{~cm}$ for LA diameter, and $5 \pm 38 \mathrm{~ms}$ for EDT.

Left ventricular (LV) mass was calculated by the cube formula at end-diastole ( $\mathrm{LV}$ mass $=0.8 \times[1.04 \times$ interventricular septum thickness $+\mathrm{LV}$ internal diameter + posterior wall thickness $\left.\left.\}^{3}-\{\mathrm{LV} \text { internal diameter }\}^{3}\right]+0.6 \mathrm{~g}\right)$ [20]. Relative wall thickness (RWT) was calculated as (relative wall thickness $=[2 \mathrm{x}$ posterior wall thickness $] / \mathrm{LV}$ internal diameter at end-diastole) [20]. We indexed LA size and LV mass by body surface area calculated by the Du Bois formula (body surface area $=\left[\right.$ weight $\{\mathrm{kg}\}{ }^{0.425} \times$ height $\left.\left.\{\mathrm{cm}\}^{0.725}\right] \times 0.007184\right)$.

\section{Diastolic dysfunction}

We used measurements of LA size, LV remodeling, tissue Doppler and Doppler of mitral flow as parameters of DD, and the cut-offs were set according to previously published data and international guidelines [1, 20-22]. We defined LA size as normal $\left(<2.2 \mathrm{~cm} / \mathrm{m}^{2}\right)$, moderately enlarged $\left(2.2-2.79 \mathrm{~cm} / \mathrm{m}^{2}\right)$ and severely enlarged $\left(\geq 2.8 \mathrm{~cm} / \mathrm{m}^{2}\right)$. Isovolumetric relaxation time (IVRT) was either reduced (<60 ms), normal $(60-110 \mathrm{~ms})$, or prolonged ( $>110 \mathrm{~ms})$. LV hypertrophy was defined as LV mass $>95 \mathrm{~g} / \mathrm{m}^{2}$ in women and $>115 \mathrm{~g} / \mathrm{m}^{2}$ in men. LV remodeling was defined as normal, concentric remodeling (no hypertrophy and RWT >0.42), concentric hypertrophy (hypertrophy and RWT $>0.42$ ), and eccentric remodeling (hypertrophy and RWT $\leq 0.42$ ). The early myocardial peak velocity of the mitral annulus, tissue Doppler e' wave (the average of the septal e' and lateral e' measurements), was defined as decreased $(<9 \mathrm{~cm} / \mathrm{s})$ or normal $(\geq 9 \mathrm{~cm} / \mathrm{s})$. E/e, the ratio of peak early LV filling (E-wave) and average tissue Doppler e' wave, was stratified into normal $(<8)$ and increased $(\geq 8)$. E/A ratio, the ratio of the E-wave and peak late LV filling (A-wave), was divided into low $(<1.0)$, normal (1.0-2.0) and high (>2.0). We defined EDT, the deceleration time of early filling velocity, into low $(<140 \mathrm{~ms})$, normal (140-220 ms) and high (> $220 \mathrm{~ms})$.

\section{Statistics}

The population characteristics are given as number and percentage of total or mean $\pm S D$, except for albumincreatinine ratio, which is given as median and interquartile range. Independent sample t-tests and chi square tests were applied to compare baseline variables between women and men. For each of the indices of DD, we tested the associations with the continuous variable of adiponectin or adiponectin divided into the lowest sexspecific tertile vs. all others, and the covariates sex, age, waist circumference, mean systolic blood pressure, mean diastolic blood pressure, physical activity, smoking, use of blood pressure lowering drugs, total cholesterol, HDL cholesterol, triglycerides, eGFR, and albumin-creatinine ratio. In analyses with dichotomized indices of $\mathrm{DD}$, we employed multivariable binary logistic regression models, and in analyses assessing markers of DD classified into more than two categories (i.e. E/A ratio, EDT, IVRT, LV remodeling and LA size) we used multivariable multinomial logistic regression models, with the normal categories as references. The indices of DD were the dependent variables in these analyses, and adiponectin was the independent variable of interest. We also did the analyses with a combined variable for DD: average e' wave $<9$ plus LA size $\geq 2.2 \mathrm{~cm} / \mathrm{m}^{2}$, an approximation of a definition of DD given by guidelines [23]. We tested for interaction between sex and adiponectin for the association with each echocardiographic marker of DD using two-way cross products between sex and the continuous variable of adiponectin or the indicator variable of adiponectin divided into lowest sex-specific tertile vs. all others. With the same covariates as listed above, we examined the association of adiponectin with the two continuous variables of cardiac remodeling, LV mass and LA size, with linear regression analyses. We tested for non-linearity by applying fractional polynomial models, which estimated the best prediction of the outcome variable from the power transformations $-2,-1$, $0.5,0$ (log transformation), $0.5,1,2,3$, on the same linear regression models. We tested for interaction between sex 
and adiponectin for the association with the continuous variables using two-way cross products between sex and adiponectin as a continuous variable. A two-sided $p$-value of $<0.05$ was considered significant. We performed all the analyses with SPSS software (IBM Corp. Released 2015. IBM SPSS Statistics for Windows, Version 23.0. Armonk, NY: IBM Corp), except for the polynomial fractional analyses, which were done with Stata software (StataCorp. 2015. Stata Statistical Software: Release 14. College Station, TX: StataCorp LP).

\section{Results}

\section{Population characteristics}

The indices of DD and cardiac remodeling examined in the present study are listed in Table 1, along with the number of men and women with each echocardiographic marker of DD.

The population characteristics, specified for sex, are given in Table 2. Most biometrics, including age, differed significantly between the sexes. This included the echocardiography parameters, except for E/A ratio. Of the non-echocardiographic variables, only systolic blood pressure, eGFR, albumin-creatinine ratio, daily smokers, and use of blood pressure lowering drugs did not significantly differ between the sexes.

\section{Multivariable regression models}

Multivariable logistic regressions with the indices of DD that were significantly associated with adiponectin (i.e., average $\mathrm{e}^{\prime}<9$, LA size $\geq 2.8 \mathrm{~cm} / \mathrm{m}^{2}$ ) as the dependent variables are shown in Table 3. Decreased adiponectin was associated with significantly higher odds of having average $e^{\prime}<9$. On the other hand, lower adiponectin was associated with reduced odds of severely enlarged LA size. There were no significant associations between continuous adiponectin and the indicator variables for $\mathrm{E} / \mathrm{A}$ ratio, E/e' ratio, EDT, IVRT, or LV remodeling, nor for moderately enlarged atria (not shown).

Table 4 displays the continuous variables for LV mass and LA size as dependent, and adiponectin as the independent variable of interest in multivariable linear regression models. Adiponectin was significantly and positively associated with LA size. Figure 1 shows the result of multivariable fractional polynomial regression and the non-linear (fractional power $3, p<0.001$ ) relationship between adiponectin and LA size, which had a better fit than the linear model. Uric acid did not interact significantly with adiponectin for any of the analyses.

\section{Sex differences}

Significant interaction between adiponectin (continuous variable) and sex was found for the association with two markers of $\mathrm{DD}$, average $\mathrm{e}^{\prime}<9$ and $\mathrm{E} / \mathrm{e}^{\prime}$ ratio $\geq 8$. Sex stratified logistic regression analyses for these markers are illustrated in Fig. 2. Lower adiponectin was associated with higher odds of average $\mathrm{e}^{\prime}<9$ in women (odds ratio [OR] 1.17 per $1 \mu \mathrm{g} / \mathrm{mL}$ adiponectin decrease, 95\% confidence interval $[\mathrm{CI}] 1.04-1.30, p=0.01)$, but not

Table 1 Indices of diastolic dysfunction and LV remodeling

\begin{tabular}{|c|c|c|c|c|}
\hline Index & Normal values & $\begin{array}{l}\text { Diastolic dysfunction and } \\
\text { LV remodeling }\end{array}$ & $\begin{array}{l}\text { Women with index at } \\
\text { baseline, } \mathrm{n}(\%)\end{array}$ & $\begin{array}{l}\text { Men with index at baseline, } \\
\mathrm{n}(\%)\end{array}$ \\
\hline E/A ratio & $1.0-2.0$ & $<1.0 ;>2.0$ & $\begin{array}{l}<1.0: n=629(54.0 \%) \\
>2.0: n=12(1.0 \%)\end{array}$ & $\begin{array}{l}<1.0: n=505(58.8 \%) \\
>2.0: n=14(1.6 \%)\end{array}$ \\
\hline EDT & $140-220 \mathrm{~ms}$ & $<140 \mathrm{~ms} ;>220 \mathrm{~ms}$ & $\begin{array}{l}<140 \mathrm{~ms}: n=120(10.3 \%) \\
>220 \mathrm{~ms} ; n=163(14.0 \%)\end{array}$ & $\begin{array}{l}<140 \mathrm{~ms}: n=73(8.1 \%) \\
>220 \mathrm{~ms} ; n=188(21.0 \%)\end{array}$ \\
\hline IVRT & $60-110 \mathrm{~ms}$ & $<60 \mathrm{~ms}_{;}>110 \mathrm{~ms}$ & $\begin{array}{l}<60 \mathrm{~ms}: n=25(2.1 \%) \\
>110 \mathrm{~ms}: n=23(2.0 \%)\end{array}$ & $\begin{array}{l}<60 \mathrm{~ms}: n=12(1.3 \%) \\
>110 \mathrm{~ms}: n=29(3.2 \%)\end{array}$ \\
\hline Average e' wave & $\geq 9 \mathrm{~cm} / \mathrm{s}$ & $<9 \mathrm{~cm} / \mathrm{s}$ & $n=184(15.8 \%)$ & $n=125(14.0 \%)$ \\
\hline E/e' ratio & $<8$ & $\geq 8$ & $n=247(21.2 \%)$ & $n=149(16.6 \%)$ \\
\hline LA size & $<2.2 \mathrm{~cm} / \mathrm{m}^{2}$ & $\begin{array}{l}\text { Moderately enlarged: } \\
2.2-2.79 \mathrm{~cm} / \mathrm{m}^{2} \text {; severely } \\
\text { enlarged: } \geq 2.8 \mathrm{~cm} / \mathrm{m}^{2}\end{array}$ & $\begin{array}{l}\text { Moderately enlarged: } \\
n=319(27.4 \%) ; \text { severely } \\
\text { enlarged: } n=26(2.2 \%)\end{array}$ & $\begin{array}{l}\text { Moderately enlarged: } \\
n=176(19.6 \%) ; \text { severely } \\
\text { enlarged: } n=14(1.6 \%)\end{array}$ \\
\hline LV remodeling & $\begin{array}{l}\mathrm{LV} \text { mass } \leq 95 \mathrm{~g} / \mathrm{m}^{2} \text { in } \\
\text { women or } \leq 115 \mathrm{~g} / \mathrm{m}^{2} \\
\text { in men, and RWT } \leq 0.42\end{array}$ & $\begin{array}{l}\text { Concentric remodeling: } \\
\text { LV mass } \leq 95 \mathrm{~g} / \mathrm{m}^{2} \text { in } \\
\text { women or } \leq 115 \mathrm{~g} / \mathrm{m}^{2} \\
\text { in men, and RWT }>0.42 ; \\
\text { concentric hypertrophy: } \\
\text { LV mass }>95 \mathrm{~g} / \mathrm{m}^{2} \text { in } \\
\text { women or }>115 \mathrm{~g} / \mathrm{m}^{2} \\
\text { in men, and RWT }>0.42 ; \\
\text { eccentric hypertrophy: LV } \\
\text { mass }>95 \mathrm{~g} / \mathrm{m}^{2} \text { in women } \\
\text { or }>115 \mathrm{~g} / \mathrm{m}^{2} \text { in men, } \\
\text { and RWT } \leq 0.42\end{array}$ & $\begin{array}{l}\text { Concentric remodeling: } \\
n=45 \text { (3.9\%); concentric } \\
\text { hypertrophy: } n=40 \text { (3.4\%); } \\
\text { eccentric hypertrophy: } \\
n=206(17.7 \%)\end{array}$ & $\begin{array}{l}\text { Concentric remodeling: } \\
n=39 \text { (4.4\%); concentric } \\
\text { hypertrophy: } \\
n=35(3.9 \%) ; \text { eccentric } \\
\text { hypertrophy: } n=147(16.4 \%)\end{array}$ \\
\hline
\end{tabular}


Table 2 Baseline characteristics of cohort divided by sex $(n=2061)$

\begin{tabular}{|c|c|c|c|c|c|}
\hline \multirow[b]{2}{*}{ Age, years } & \multicolumn{2}{|c|}{ Women $(n=1165)$} & \multicolumn{2}{|c|}{ Men $(n=896)$} & \multirow{2}{*}{$\begin{array}{l}\mathrm{P} \text { between sex } \\
0.004\end{array}$} \\
\hline & 64.2 & \pm 11.7 & 65.6 & \pm 10.4 & \\
\hline Adiponectin, $\mu \mathrm{g} / \mathrm{mL}$ & 4.64 & \pm 2.07 & 3.16 & \pm 1.48 & $<0.001$ \\
\hline Uric acid, $\mu \mathrm{mol} / \mathrm{L}$ & 280.2 & \pm 66.3 & 349.1 & \pm 71.5 & $<0.001$ \\
\hline Systolic blood pressure, $\mathrm{mm} \mathrm{Hg}$ & 141.7 & \pm 26.2 & 143.5 & \pm 20.6 & 0.094 \\
\hline Diastolic blood pressure, $\mathrm{mm} \mathrm{Hg}$ & 76.5 & \pm 10.3 & 81.7 & \pm 10.3 & $<0.001$ \\
\hline $\mathrm{BMI}, \mathrm{kg} / \mathrm{m}^{2}$ & 26.4 & \pm 4.3 & 27.2 & \pm 3.6 & $<0.001$ \\
\hline Waist circumference, $\mathrm{cm}$ & 91.0 & \pm 11.3 & 100.1 & \pm 10.2 & $<0.001$ \\
\hline Total cholesterol, $\mathrm{mmol} / \mathrm{L}$ & 5.89 & \pm 1.07 & 5.57 & \pm 1.11 & $<0.001$ \\
\hline Serum HDL, mmol/L & 1.72 & \pm 0.43 & 1.42 & \pm 0.40 & $<0.001$ \\
\hline Triglycerides, $\mathrm{mmol} / \mathrm{L}$ & 1.37 & \pm 0.70 & 1.53 & \pm 0.88 & $<0.001$ \\
\hline $\mathrm{eGFR}, \mathrm{mL} / \mathrm{min} / 1.73 \mathrm{~m}^{2}$ & 89.6 & \pm 17.9 & 86.6 & \pm 14.5 & 0.187 \\
\hline Albumin-creatinine ratio, $\mathrm{mg} / \mathrm{mmol}$ & 0.36 & {$[0.21-0.73]$} & 0.37 & {$[0.17-0.87]$} & 0.798 \\
\hline Daily smoking, $\mathrm{n}$ & 210 & $18.0 \%$ & 141 & $15.7 \%$ & 0.171 \\
\hline Physically active, $\mathrm{n}$ & 316 & $27.1 \%$ & 285 & $31.8 \%$ & 0.020 \\
\hline Use of blood pressure lowering drugs, $n$ & 383 & $32.9 \%$ & 312 & $34.8 \%$ & 0.354 \\
\hline Left ventricular mass, $\mathrm{g} / \mathrm{m}^{2}$ & 84.1 & \pm 21.5 & 101.0 & \pm 26.7 & $<0.001$ \\
\hline Left atrial size, $\mathrm{cm} / \mathrm{m}^{2}$ & 2.09 & \pm 0.30 & 2.02 & \pm 0.28 & $<0.001$ \\
\hline E-wave deceleration time, ms & 182.5 & \pm 43.8 & 193.7 & \pm 51.2 & $<0.001$ \\
\hline E/A ratio & 1.02 & \pm 0.34 & 0.99 & \pm 0.35 & 0.080 \\
\hline Left ventricular ejection fraction, $\%$ & 72.1 & \pm 7.8 & 68.7 & \pm 8.8 & 0.033 \\
\hline Left ventricular ejection fraction $<50 \%, n$ & 7 & $0.6 \%$ & 14 & $1.6 \%$ & 0.032 \\
\hline Average $e^{\prime}, \mathrm{cm} / \mathrm{s}$ & 11.28 & \pm 2.58 & 10.97 & \pm 2.24 & 0.005 \\
\hline E/e' ratio & 6.88 & \pm 2.09 & 6.50 & \pm 1.98 & $<0.001$ \\
\hline
\end{tabular}

$T$-test or chi square were used to compare values between men and women The Tromsø Study

Values are given as mean (SD), median (IQR), or number (\%)

Abbreviations: BMI Body mass index, eGFR estimated glomerular filtration rate, HDL High-density lipoprotein

men (OR 0.99, 95\% CI 0.85-1.16, $p=0.93$ ), $\mathrm{p}$ for interaction between adiponectin and sex was 0.04. Lower adiponectin was associated with higher odds of $E / \mathrm{e}^{\prime}$ ratio $\geq 8$ in women (OR 1.12 per $1 \mu \mathrm{g} / \mathrm{mL}$ adiponectin decrease, $95 \%$ CI $1.02-1.24, P=0.02$ ), but not in men (OR 0.90, 95\% CI 0.78-1.03, $p=0.13$, p for interaction between adiponectin and sex 0.04 ).

Figures 3 and 4 display the indices of DD for which sex and the categorized adiponectin variable interacted significantly, namely LV remodeling and LA size. Adiponectin values in the lower tertile was associated with increased odds of concentric LV hypertrophy (OR 2.44, 95\% CI 1.03-5.77, $p=0.04$ ) in women, but in men reduced odds for the same outcome (OR 0.32, 95\% CI 0.11-0.88, $p=0.03$, p for interaction with sex 0.002), compared to normal LV architecture, as shown in Fig. 3. Moreover, adiponectin in the lower tertile was associated with lower odds of eccentric LV hypertrophy in men (OR 0.53, 95\% CI $0.33-0.88, p=0.01$ ), but not women (OR 1.07, 95\% CI $0.71-1.62, p=0.74 \mathrm{p}$ for interaction 0.02 ).
Figure 4 illustrates the ORs of the association between adiponectin and LA size divided by sex. Compared to normal LA size, adiponectin in the lower tertile was associated with moderately enlarged LA in women (OR $1.43,95 \%$ CI 1.01-2.03, $p=0.04$ ), but not in men (OR $1.01,95 \%$ CI $0.64-1.58, p=0.98, \mathrm{p}$ for interaction with sex 0.04). There was no significant association between severely enlarged LA and adiponectin for either sex.

Multivariable fractional polynomial regression revealed that lower adiponectin was associated with increased LV mass in women (fractional power $-2, p=0.001$ ), but not men $(p=0.66, \mathrm{p}$ for interaction with sex 0.01$)$, as displayed in Fig. 5a and b, respectively.

For a combination variable of DD consisting of subjects with both LA size $\geq 2.2 \mathrm{~cm} / \mathrm{m}^{2}$ and average $\mathrm{e}^{\prime}<9$, the indicator variable of low adiponectin (lower sex-specific tertile vs. all others) interacted with sex $(p=0.03)$. However, adiponectin did not significantly predict this outcome for neither women (OR 1.39, 95\% CI $0.98-1.97, p=0.07$ ) nor men (OR $0.95,95 \%$ CI $0.61-1.50, p=0.83)$. 
Table 3 Multivariable logistic regression models with some indices of diastolic dysfunction as dependent variables

\begin{tabular}{|c|c|c|c|c|c|c|}
\hline & Average e' & & & $\underline{L A}$ size $\geq 2$ & $m^{2 a}$ & \\
\hline & Odds ratio & $95 \% \mathrm{Cl}$ & $P$ value & Odds ratio & $95 \% \mathrm{Cl}$ & $P$ value \\
\hline Adiponectin (per $1 \mu \mathrm{g} / \mathrm{mL}$ decrease) & 1.12 & {$[1.02-1.22]$} & 0.015 & 0.78 & {$[0.66-0.93]$} & 0.004 \\
\hline Uric acid (per 59 umol/L increase) & 1.08 & {$[0.94-1.25]$} & 0.282 & 1.68 & {$[1.21-2.32]$} & 0.002 \\
\hline Sex (male vs. female) & 0.59 & {$[0.41-0.86]$} & 0.005 & 0.54 & {$[0.19-1.49]$} & 0.233 \\
\hline Age (per 5 year increase) & 1.76 & {$[1.56-1.99]$} & $<0.001$ & 2.52 & {$[1.76-3.57]$} & $<0.001$ \\
\hline Waist circumference (per $5 \mathrm{~cm}$ increase) & 1.00 & {$[0.93-1.08]$} & 0.971 & 0.77 & {$[0.91-0.99]$} & 0.009 \\
\hline $\begin{array}{l}\text { Mean systolic blood pressure (per } 5 \text { mm Hg } \\
\text { increase) }\end{array}$ & 1.05 & {$[1.01-1.09]$} & 0.025 & 1.01 & {$[0.91-1.11]$} & 0.888 \\
\hline $\begin{array}{l}\text { Mean diastolic blood pressure (per } 5 \mathrm{~mm} \mathrm{Hg} \\
\text { increase) }\end{array}$ & 1.15 & {$[1.05-1.25]$} & 0.002 & 0.95 & {$[0.77-1.16]$} & 0.584 \\
\hline $\begin{array}{l}\text { Albumin-creatinine ratio (per } 1 \mathrm{mg} / \mathrm{mmol} \\
\text { increase) }\end{array}$ & 1.01 & {$[0.99-1.02]$} & 0.334 & 1.04 & {$[1.01-1.06]$} & 0.007 \\
\hline Total cholesterol (per $1 \mathrm{mmol} / \mathrm{L}$ increase) & 0.90 & {$[0.77-1.04]$} & 0.142 & 1.10 & {$[0.75-1.62]$} & 0.615 \\
\hline HDL cholesterol (per 1 mmol/L increase) & 1.17 & {$[0.75-1.82]$} & 0.497 & 0.30 & {$[0.09-1.04]$} & 0.057 \\
\hline Triglycerides (per 1 mmol/L increase) & 1.19 & {$[0.94-1.51]$} & 0.146 & 0.67 & {$[0.29-1.56]$} & 0.352 \\
\hline eGFR (per $5 \mathrm{~mL} / \mathrm{min} / 1.73 \mathrm{~m}^{2}$ increase) & 1.02 & {$[0.96-1.08]$} & 0.609 & 1.17 & {$[1.01-1.36]$} & 0.040 \\
\hline Daily smoking (yes vs. no) & 1.47 & {$[0.99-2.19]$} & 0.059 & 1.72 & {$[0.59-5.01]$} & 0.318 \\
\hline Physically active (yes vs. no) & 1.08 & {$[0.76-1.53]$} & 0.672 & 1.42 & {$[0.51-3.90]$} & 0.500 \\
\hline $\begin{array}{l}\text { Use of blood pressure lowering drugs } \\
\text { (yes vs. no) }\end{array}$ & 1.26 & {$[0.92-1.71]$} & 0.148 & 2.17 & {$[0.95-4.93]$} & 0.065 \\
\hline
\end{tabular}

The Tromsø Study

Covariates: Age, sex, waist circumference, mean systolic blood pressure, mean diastolic blood pressure, use of blood pressure lowering drugs, total cholesterol, $\mathrm{HDL}$ cholesterol, triglycerides, eGFR, albumin-creatinine ratio, physically active, daily smoker and uric acid

Abbreviations: eGFR estimated glomerular filtration rate, $H D L$ high-density lipoprotein, $L A$ left atrium

${ }^{a}$ Compared to reference category, LA size $<2.2 \mathrm{~cm} / \mathrm{m}^{2}$

\section{Discussion}

To our knowledge, this is the first study to demonstrate sex differences in the association between adiponectin and DD in a general, non-diabetic population. In this study of 1165 women and 896 men, we have shown that a lower adiponectin was associated with higher odds of indices of DD in women, including $\mathrm{e}^{\prime}<9, \mathrm{E} / \mathrm{e}^{\prime}$ ratio $\geq 8$, concentric LV hypertrophy, and moderately enlarged LA. In addition, lower adiponectin was associated with higher LV mass in women. These associations were not found in men. Rather, low adiponectin was associated

Table 4 Linear regression models with parameters of cardiac remodeling as dependent variables

\begin{tabular}{lcccc}
\hline & \multicolumn{4}{c}{ Adiponectin (per 1 $\mu \mathrm{g} / \mathrm{mL}$ increase) } \\
\cline { 2 - 5 } & $\beta$ & $95 \% \mathrm{Cl}$ & $\mathrm{t}$ & P value \\
\hline $\begin{array}{l}\text { Left ventricular } \\
\text { mass }\left(\mathrm{g} / \mathrm{m}^{2}\right)\end{array}$ & -0.59 & -1.29 to 0.11 & -1.66 & 0.098 \\
$\begin{array}{l}\text { Left atrial size } \\
\left(\mathrm{cm} / \mathrm{m}^{2}\right)\end{array}$ & 0.013 & 0.01 to 0.02 & 3.29 & 0.001
\end{tabular}

The Tromsø Study

Covariates: Age, sex, waist circumference, mean systolic blood pressure, mean diastolic blood pressure, use of blood pressure lowering drugs, total cholesterol, high-density lipoprotein cholesterol, triglycerides, estimated glomerular filtration rate, albumin-creatinine ratio, physically active, daily smoker and uric acid

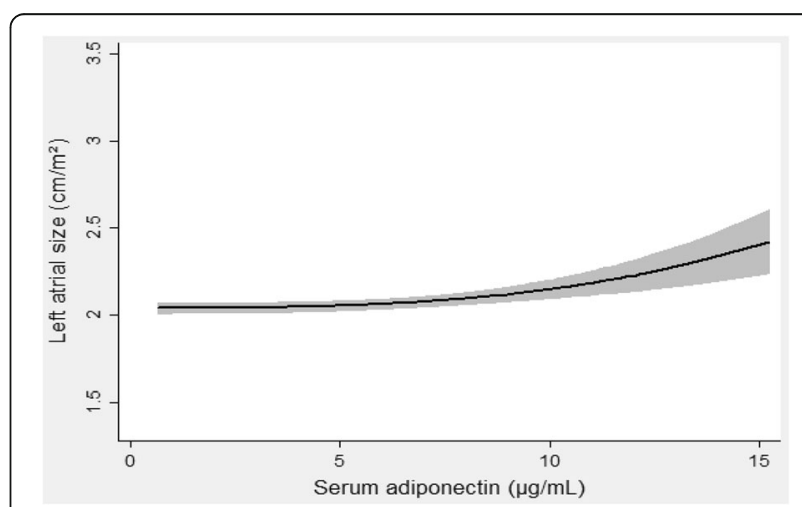

Fig. 1 Multivariable fractional polynomial regression with left atrial size as the dependent variable, and adiponectin as the independent variable of interest. Shaded regions denote 95\% confidence interval. Covariates: Age, sex, waist circumference, mean systolic blood pressure, mean diastolic blood pressure, use of blood pressure lowering drugs, total cholesterol, high-density lipoprotein, triglycerides, estimated glomerular filtration rate, physically active, daily smoker, albumin-creatinine ratio and uric acid 


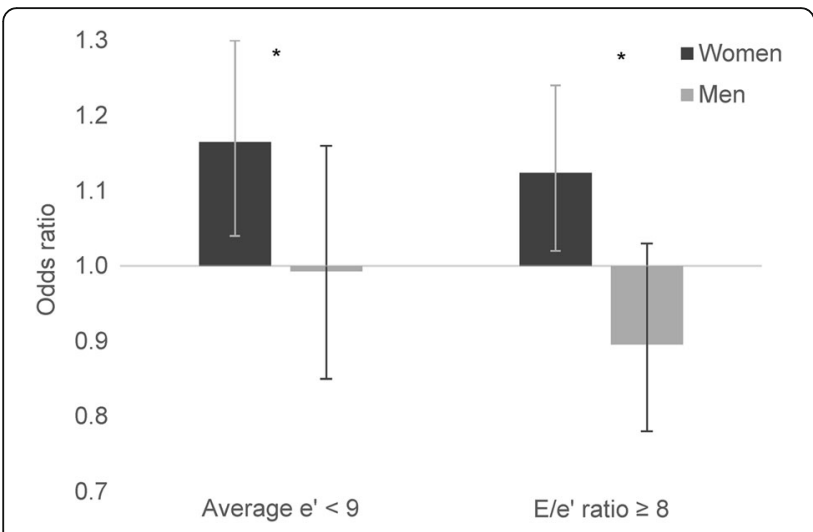

Fig. 2 Multivariable binary logistic regression models divided by sex with average $\mathrm{e}^{\prime}<9$ and $\mathrm{E} / \mathrm{e}^{\prime}$ ratio $\geq 8$ as dependent variables. Odds ratio are per $1 \mu \mathrm{g} / \mathrm{mL}$ adiponectin decrease. Whiskers represent $95 \%$ confidence interval. ${ }^{*}=p$ for interaction with sex $<0.05$. Covariates: Age, waist circumference, mean systolic blood pressure, mean diastolic blood pressure, use of blood pressure lowering drugs, total cholesterol, high-density lipoprotein, triglycerides, estimated glomerular filtration rate, physically active, daily smoker, albumin-creatinine ratio and uric acid

with decreased odds of concentric LV hypertrophy and eccentric LV hypertrophy in men. Except for a severely enlarged atrium, we found no marker of DD that was associated with a high adiponectin in women, and conversely, we found no marker of DD at all that was associated with a low adiponectin in men.

Traditionally, high adiponectin levels have been regarded as favorable in terms of cardiac health, but research has challenged this view, and the role and action of adiponectin in heart disease is not clear. In general, low adiponectin has been associated with the development of coronary heart disease in healthy subjects [24], but high adiponectin was a risk factor for severity of HF

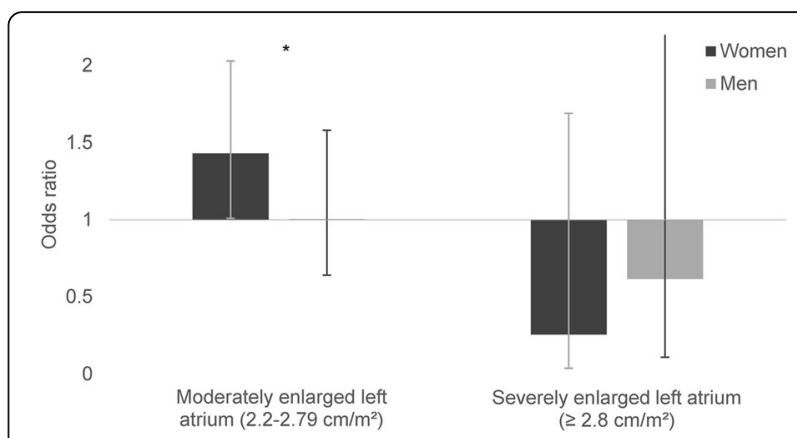

Fig. 4 Multivariable multinomial logistic regression models divided by sex with left atrial size as the dependent variable. Each category of left atrial size displayed is compared to normal category, left atrial size $<2.2 \mathrm{~cm} / \mathrm{m}^{2}$. Odds ratios are for the individuals in the sex-specific lower adiponectin tertile compared to the two upper tertiles. Whiskers represent $95 \%$ confidence interval. ${ }^{*}=p$ for interaction with sex $<0.05$. Covariates: Age, waist circumference, mean systolic blood pressure, mean diastolic blood pressure, use of blood pressure lowering drugs, total cholesterol, high-density lipoprotein, triglycerides, estimated glomerular filtration rate, physically active, daily smoker, albumin-creatinine ratio and uric acid

and mortality in patients with chronic HF [25]. A current theory to this equivocal relationship of adiponectin and heart disease is that high levels are beneficent in healthy subjects, but that adiponectin levels can be upgraded as a compensatory mechanism in the face of chronic HF [14]. This may explain, in our study, why in women low adiponectin was associated with moderately enlarged LA, but higher adiponectin was associated with severely enlarged LA. Adiponectin could also increase simply due to reduced kidney function, which commonly coexists with HF [26].

To our knowledge, only a few studies have examined sex differences in the association between adiponectin and DD. In one paper, a cohort consisting of 193

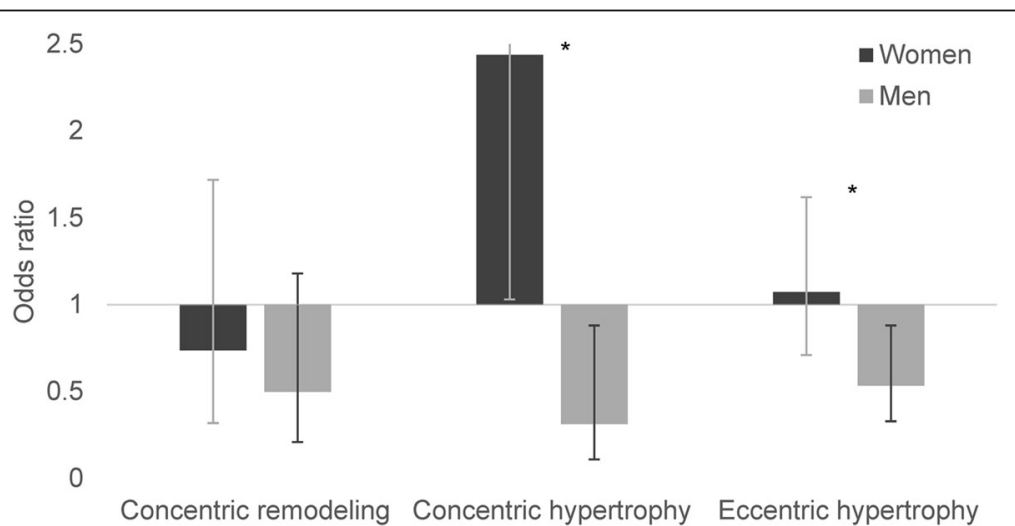

Fig. 3 Multivariable multinomial logistic regression models divided by sex with left ventricular remodeling as the dependent variable. Each category of left ventricular remodeling displayed is compared to the normal category. Odds ratios are for the individuals in the sex-specific lower adiponectin tertile compared to the two upper tertiles. Whiskers represent $95 \%$ confidence interval. ${ }^{*}=p$ for interaction with sex $<0.05$. Covariates: Age, waist circumference, mean systolic blood pressure, mean diastolic blood pressure, use of blood pressure lowering drugs, total cholesterol, high-density lipoprotein, triglycerides, estimated glomerular filtration rate, physically active, daily smoker, albumin-creatinine ratio and uric acid 


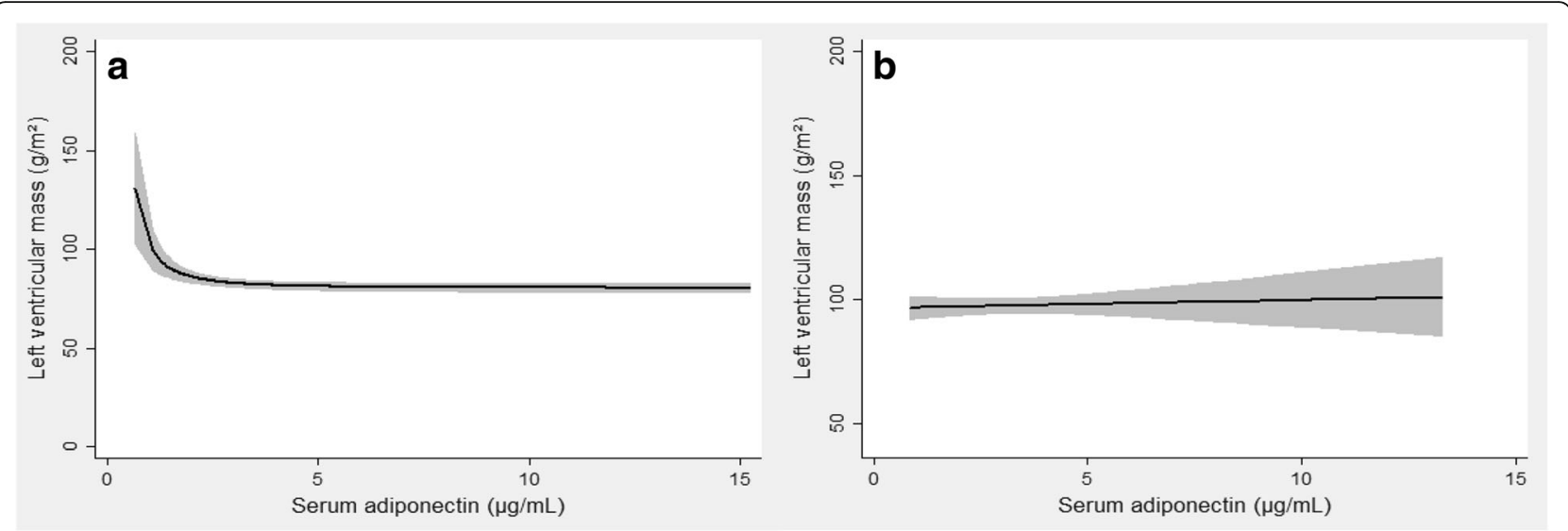

Fig. 5 Multivariable fractional polynomial regression with left ventricular mass as the dependent variable, and adiponectin as the independent variable of interest with cohort divided into women (a) and men (b). Shaded regions denote 95\% confidence interval. Covariates: Age, waist circumference, mean systolic blood pressure, mean diastolic blood pressure, use of blood pressure lowering drugs, total cholesterol, high-density lipoprotein, triglycerides, estimated glomerular filtration rate, physically active, daily smoker, albumin-creatinine ratio and uric acid

patients undergoing cardiac catheterization for coronary artery disease was divided by sex. The authors found a negative relationship between adiponectin and DD (evaluated by correlation with LV end-diastolic pressure, and Tau, the time constant of the decrease in LV pressure), but they could not report a significant sex difference in this association [27]. A recent population based study of 556 individuals did not find any association between DD and adiponectin for either sex [28]. The study categorized patients into DD grades: grade I (mild DD) if lateral $\mathrm{e}^{\prime}<$ $10 \mathrm{~cm} / \mathrm{s}, \mathrm{E} / \mathrm{A}$ ratio < 0.8, EDT > $200 \mathrm{~ms}$, and E/e' ratio $\leq 8$; grade II (moderate DD) if lateral $\mathrm{e}^{\prime}<10 \mathrm{~cm} / \mathrm{s}, \mathrm{E} / \mathrm{A}$ ratio $0.8-1.5$, EDT $160-200 \mathrm{~ms}$, and $\mathrm{E} / \mathrm{e}$ ' ratio 9-12; and grade III (severe DD), if lateral $\mathrm{e}^{\prime}<10 \mathrm{~cm} / \mathrm{s}, \mathrm{E} / \mathrm{A}$ ratio $\geq 2$, EDT $<160 \mathrm{~ms}$, and $\mathrm{E} / \mathrm{e}^{\prime}$ ratio $\geq 13$. The fact that our population was much larger and used somewhat different DD indices, may account for the divergent results.

Experimental studies may shed some light on the effects of adiponectin on the development of DD and the sex differences in the overall action of adiponectin. In adiponectin deficient mice, pressure overload resulted in concentric cardiac hypertrophy and mortality to a greater degree than in pressure overloaded wild type [29]. Another study in adiponectin deficient mice, in which the animals were subjected to aldosterone-induced hypertension in addition to uninephrectomy, showed that hypoadiponectinaemia exacerbated hypertension-induced DD with increased LV mass, increased E/A ratio, reduced e' wave and increased $\mathrm{E} / \mathrm{e}$ ' ratio in the adiponectin deficient mice compared to the wild type [30]. Transgenic mice that overexpressed adiponectin were protected from DD after pressure overload compared to wild type [31]. Induced activity of the enzyme heme oxygenase-1 ( $\mathrm{HO}-1)$ has been associated with reduced oxidative stress, increased insulin sensitivity and increased adiponectin levels [32, 33]. One study pharmacologically induced $\mathrm{HO}-1$ in both lean and obese female and male mice, and discovered that although female obese mice had higher levels of several inflammatory cytokines than male obese mice, HO-1 induction and a subsequent increase in adiponectin, reduced inflammatory cytokines to similar levels in females and males [34]. Similar results were found in another study on obese female and male mice that administered a peptide that increased HO-1 and adiponectin levels [35], and the effects were independent of body weight in the female animals only. In both these studies, adiponectin levels were similar in obese male and female mice, but treatment raised adiponectin levels significantly higher in females than males. These animal studies are suggestive of sex differences in concentration/production and activity of adiponectin, especially in the obese subjects. Indeed, adiponectin levels are generally higher in women than in men, perhaps in part because of a negative correlation with testosterone [36], and post-menopausal women have lower levels of adiponectin [37]. Also in humans, the relative sex difference in adiponectin is less pronounced in obese than non-obese [38]. Additionally, one study found DD to be more strongly correlated with abdominal adiposity in women than in men [24]. Although several studies have confirmed a positive correlation between insulin sensitivity and adiponectin in both sexes [38], one study found a lower number of adiponectin receptors in female skeletal muscle and speculates that this may result in a reduced insulin sensitizing effect of adiponectin in women compared with men [39]. Adiponectin can be separated into three complexes: low molecular weight form, middle molecular weight form, and high molecular weight form (HMW), and some suggest that the ratio of HWM to total adiponectin levels is more closely associated with insulin sensitivity than total levels alone [40]. HMW adiponectin was lower in men, but not in 
women, with diabetes and coronary artery disease [41]. The dissimilarity in adiponectin levels between men and women may be due solely to a higher level of HWM in women than men [40]. Unfortunately, only total adiponectin was available in our survey, so it was not possible for us to examine the HMW fraction in relation to DD and sex. In sum, it is possible that discrepancies between men and women in adipose tissue activity, distribution of adiponectin receptors and HMW adiponectin content have contributed to the sex differences in the association between adiponectin and DD reported in our study. With the above in mind, the facts that our cohort had a mean BMI $>25 \mathrm{~kg} /$ $\mathrm{m}^{2}$, i.e. within the overweight range, and a mean age in the mid-sixties may have influenced our results. The relationship between adiponectin, obesity, sex, and organ damage is a complex one and further studies are clearly needed.

The main strengths of this study were the large cohort size, the high attendance rate and the ability to correct for several covariates, including eGFR and use of antihypertensive medication, and the use of the newest guideline based definitions of DD. The most important limitation was its cross-sectional design. Other relevant limitations include the lack of fasting blood samples, and the single measurement of total adiponectin available. A quantification of HMW adiponectin could have provided more data in our models. Moreover, our estimation of LA was based on the diameter; LA volume measurements may have yielded additional information. Data on tricuspid regurgitation velocity would also have strengthened the study. Our exclusion of subjects with diabetes may be a further limitation. The fact that our cohort largely consisted of middle-aged, healthy Northern Europeans limits the study's generalizability to other ethnic groups.

\section{Conclusions}

Low adiponectin was associated with several indices of DD and increased LV mass in women, but not in men. Whether these associations are clinically relevant and could influence prediction and treatment of DD, should be further explored.

\footnotetext{
Abbreviations

BMI: Body mass index; Cl: Confidence interval; DD: Diastolic dysfunction; E/A ratio: Ratio of peak early LV filling (E-wave) and peak late LV filling (A-wave); E/e' ratio: Ratio of E-wave and $e^{\prime}$ wave; $\mathrm{e}^{\prime}$ : Early myocardial peak velocity of the mitral annulus; EDT: E-wave deceleration time; eGFR: Estimated glomerular filtration rate; HDL: High-density lipoprotein cholesterol; HF: Heart failure; HFpEF: Heart failure with preserved ejection fraction; HMW: High molecular weight; HO-1: Heme oxygenase-1; IVRT: Isovolumetric relaxation time; LA: Left atrium; LV: Left ventricle; OR: Odds ratio; RWT: Relative wall thickness
}

\section{Acknowledgements}

None.

\section{Funding}

This study was funded by grants from Northern Norway Regional Health Authority (Helse Nord).

\section{Availability of data and materials}

The dataset supporting the conclusions of this article is legally restricted. It will therefore not be shared publicly. However, meta-data as well as general information about the study is available at http://tromsoundersokelsen.uit.no/tromso.

\section{Authors' contributions}

Study design: JVN and MDS. Data analyses: JVN, HS, and MDS. Writing the first draft: JVN and MDS. Data interpretation, discussion and preparation of the final manuscript: JVN, HS, KY, TGJ, SNZ, AEE, BOE, and MDS. All authors read and approved the final manuscript.

\section{Competing interests}

The authors declare that they have no competing interests.

\section{Consent for publication \\ Not applicable.}

\section{Ethics approval and consent to participate}

The Regional Committee for Medical and Health Research Ethics, region north (REK north) approved the study (committee's reference number 2009/2536-3), and all participants gave their informed and written consent to participate. The Tromsø Study complies with the Declaration of Helsinki.

\section{Publisher's Note}

Springer Nature remains neutral with regard to jurisdictional claims in published maps and institutional affiliations.

\section{Author details}

${ }^{1}$ Metabolic and Renal Research Group, UiT The Arctic University of Norway, N-9037 Tromsø, Norway. ${ }^{2}$ Section of Nephrology, University Hospital of North Norway, N-9038 Tromsø, Norway. ${ }^{3}$ Department of Cardiology, University Hospital of North Norway, N-9038 Troms $\varnothing$, Norway. ${ }^{4}$ Department of Transplant Medicine, Oslo University Hospital Rikshospitalet, N-0424 Oslo, Norway. ${ }^{5}$ Department of Community Medicine, UiT The Arctic University of Norway, N-9037 Troms $\varnothing$, Norway. ${ }^{6}$ Cardiovascular Research Group IMB, UiT The Arctic University of Norway, N-9037 Tromsø, Norway. ${ }^{7}$ Cardiovascular Research Group IKM, UiT The Arctic University of Norway, N-9037 Tromsø, Norway.

Received: 29 October 2016 Accepted: 4 March 2017

Published online: 14 March 2017

\section{References}

1. Ponikowski P, Voors AA, Anker SD, Bueno H, Cleland JGF, Coats AJS, et al. 2016 ESC guidelines for the diagnosis and treatment of acute and chronic heart failure. Eur Heart J. 2016;37:2129-2200m.

2. Yancy CW, Jessup M, Bozkurt B, Butler J, Casey DE, Drazner MH, et al. 2013 ACCF/AHA guideline for the management of heart failure. J Am Coll Cardiol. 2013;62:e147-239.

3. Maggioni AP, Dahlström U, Filippatos G, Chioncel O, Leiro MC, Drozdz J, et al. EUR observational research programme: regional differences and 1year follow-up results of the Heart Failure Pilot Survey (ESC-HF Pilot). Eur J Heart Fail. 2013;15:808-17.

4. Redfield MM, Jacobsen SJ, Burnett JC, Mahoney DW, Bailey KR, Rodeheffer RJ. Burden of systolic and diastolic ventricular dysfunction in the community: appreciating the scope of the heart failure epidemic. JAMA 2003;289:194-202.

5. Borlaug BA, Paulus WJ. Heart failure with preserved ejection fraction: pathophysiology, diagnosis, and treatment. Eur Heart J. 2011;32:670-9.

6. Lam CSP, Donal E, Kraigher-Krainer E, Vasan RS. Epidemiology and clinical course of heart failure with preserved ejection fraction. Eur J Heart Fail. 2011;13:18-28.

7. Nigro E, Scudiero O, Monaco ML, Palmieri A, Mazzarella G, Costagliola C, et al. New insight into adiponectin role in obesity and obesity-related diseases. Biomed Res Int. 2014;2014:658913.

8. Rega-Kaun G, Kaun C, Wojta J. More than a simple storage organ: adipose tissue as a source of adipokines involved in cardiovascular disease. Thromb Haemost. 2013;110:641-50. 
9. Yamamoto Y, Hirose H, Saito I, Nishikai K, Saruta T. Adiponectin, an adipocytederived protein, predicts future insulin resistance: two-year follow-up study in Japanese population. J Clin Endocrinol Metab. 2004;89:87-90.

10. Chow WS, Cheung BMY, Tso AWK, Xu A, Wat NMS, Fong CHY, et al. Hypoadiponectinemia as a predictor for the development of hypertension: a 5-year prospective study. Hypertension. 2007;49:1455-61.

11. Matsubara M, Maruoka S, Katayose S. Inverse relationship between plasma adiponectin and leptin concentrations in normal-weight and obese women. Eur J Endocrinol. 2002;147:173-80.

12. Ryo M, Nakamura T, Kihara S, Kumada M, Shibazaki S, Takahashi M, et al. Adiponectin as a biomarker of the metabolic syndrome. Circ J. 2004;68:975-81.

13. Persson J, Lindberg K, Gustafsson TP, Eriksson P, Paulsson-Berne G, Lundman P. Low plasma adiponectin concentration is associated with myocardial infarction in young individuals. J Intern Med. 2010;268:194-205.

14. Attanasio P, Anker SD, Doehner W, von Haehling S. Hormonal consequences and prognosis of chronic heart failure. Curr Opin Endocrinol Diabetes Obes. 2011;18:224-30

15. Baldwin W, McRae S, Marek G, Wymer D, Pannu V, Baylis C, et al. Hyperuricemia as a mediator of the proinflammatory endocrine imbalance in the adipose tissue in a murine model of the metabolic syndrome. Diabetes. 2011;60:1258-69.

16. Jacobsen BK, Eggen AE, Mathiesen EB, Wilsgaard T, Njølstad I. Cohort profile: the Tromsø study. Int J Epidemiol. 2012;41:961-7.

17. Eggen AE, Mathiesen EB, Wilsgaard T, Jacobsen BK, Njølstad I. The sixth survey of the Tromso Study (Tromso 6) in 2007-08: collaborative research in the interface between clinical medicine and epidemiology: study objectives, design, data collection procedures, and attendance in a multipurpose population-based health. Scand J Public Health. 2013;41:65-80.

18. Solbu MD, Norvik JV, Storhaug HM, Melsom T, Eggen AE, Zykova SN, et al. The association between adiponectin, serum uric acid and urinary markers of renal damage in the general population: cross-sectional data from the Tromsø study. Kidney Blood Press Res. 2016;41:623-34.

19. Inker LA, Schmid CH, Tighiouart H, Eckfeldt JH, Feldman HI, Greene T, et al, Estimating glomerular filtration rate from serum creatinine and cystatin C. N Engl J Med. 2012;367:20-9.

20. Lang RM, Badano LP, Mor-Avi V, Afilalo J, Armstrong A, Ernande L, et al. Recommendations for cardiac chamber quantification by echocardiography in adults: an update from the American society of echocardiography and the European association of cardiovascular imaging. Eur Heart J Cardiovasc Imaging. 2015;16:233-71.

21. Tiwari S, Schirmer H, Jacobsen BK, Hopstock LA, Nyrnes A, Heggelund $\mathrm{G}$, et al. Association between diastolic dysfunction and future atrial fibrillation in the Tromsø Study from 1994 to 2010. Heart. 2015;101: 1302-8.

22. Nagueh SF, Smiseth OA, Appleton CP, Byrd BF, Dokainish H, Edvardsen T, et al. Recommendations for the evaluation of left ventricular diastolic function by echocardiography: an update from the American Society of Echocardiography and the European Association of Cardiovascular Imaging. J Am Soc Echocardiogr. 2016;29:277-314.

23. Nagueh SF, Appleton CP, Gillebert TC, Marino PN, Oh JK, Smiseth OA, et al. Recommendations for the evaluation of left ventricular diastolic function by echocardiography. Eur J Echocardiogr. 2009;10:165-93.

24. Côté M, Cartier A, Reuwer AQ, Arsenault BJ, Lemieux I, Després J-P, et al. Adiponectin and risk of coronary heart disease in apparently healthy men and women (from the EPIC-Norfolk Prospective Population Study). Am J Cardiol. 2011;108:367-73.

25. Kistorp C, Faber J, Galatius S, Gustafsson F, Frystyk J, Flyvbjerg A, et al. Plasma adiponectin, body mass index, and mortality in patients with chronic heart failure. Circulation. 2005;112:1756-62.

26. Beatty AL, Zhang MH, Ku IA, Na B, Schiller NB, Whooley MA. Adiponectin is associated with increased mortality and heart failure in patients with stable ischemic heart disease: data from the Heart and Soul Study. Atherosclerosis. 2012;220:587-92.

27. Fukuta H, Ohte N, Wakami K, Goto T, Tani T, Kimura G. Relation of plasma levels of adiponectin to left ventricular diastolic dysfunction in patients undergoing cardiac catheterization for coronary artery disease. Am J Cardiol. 2011;108:1081-5.

28. Fontes-Carvalho R, Pimenta J, Bettencourt P, Leite-Moreira A, Azevedo A. Association between plasma leptin and adiponectin levels and diastolic function in the general population. Expert Opin Ther Targets. 2015;19:1283-91.
29. Shibata R, Ouchi N, Ito M, Kihara S, Shiojima I, Pimentel DR, et al. Adiponectin-mediated modulation of hypertrophic signals in the heart. Nat Med. 2004;10:1384-9.

30. Sam F, Duhaney TAS, Sato K, Wilson RM, Ohashi K, Sono-Romanelli S, et al. Adiponectin deficiency, diastolic dysfunction, and diastolic heart failure. Endocrinology. 2010;151:322-31.

31. Tanaka K, Wilson RM, Essick EE, Duffen JL, Scherer PE, Ouchi N, et al. Effects of adiponectin on calcium-handling proteins in heart failure with preserved ejection fraction. Circ Hear Fail. 2014;7:976-85.

32. Abraham NG, Junge JM, Drummond GS. Translational signi fi cance of heme oxygenase in obesity and metabolic syndrome. Trends Pharmacol Sci. 2016;37:17-36.

33. Ayer A, Zarjou A, Agarwal A, Stocker R. Heme oxygenases in cardiovascular health and disease. Physiol Rev. 2016;96:1449-508.

34. Burgess A, Li M, Vanella L, Kim DH, Rezzani R, Rodella L, et al. Adipocyte heme oxygenase-1 induction attenuates metabolic syndrome in both male and female obese mice. Hypertension. 2010;56:1124-30.

35. Marino JS, Peterson SJ, Li M, Vanella L, Sodhi K, Hill JW, et al. ApoA-1 mimetic restores adiponectin expression and insulin sensitivity independent of changes in body weight in female obese mice. Nutr Diabetes. 2012;2:e33.

36. Xu A, Chan KW, Hoo RLC, Wang Y, Tan KCB, Zhang J, et al. Testosterone selectively reduces the high molecular weight form of adiponectin by inhibiting its secretion from adipocytes. J Biol Chem. 2005;280:18073-80.

37. Ren J, Kelley RO. Cardiac health in women with metabolic syndrome: clinical aspects and pathophysiology. Obesity. 2009;17:1114-23.

38. Lundsgaard AM, Kiens B. Gender differences in skeletal muscle substrate metabolism - molecular mechanisms and insulin sensitivity. Front Endocrinol (Lausanne). 2014;5:195.

39. Høeg LD, Sjøberg KA, Lundsgaard AM, Jordy AB, Hiscock N, Wojtaszewski JFP, et al. Adiponectin concentration is associated with muscle insulin sensitivity, AMPK phosphorylation, and ceramide content in skeletal muscles of men but not women. J Appl Physiol. 2013;114:592-601.

40. Wang ZV, Scherer PE. Adiponectin, the past two decades. J Mol Cell Biol. 2016;8:93-100.

41. Aso Y, Yamamoto R, Wakabayashi S, Uchida T, Takayanagi K, Takebayashi K, et al. Comparison of serum high-molecular weight (HMW) adiponectin with total adiponectin concentrations in type 2 diabetic patients with coronary artery disease using a novel enzyme-linked immunosorbent assay to detect HMW adiponectin. Diabetes. 2006:55:1954-60.

\section{Submit your next manuscript to BioMed Central and we will help you at every step:}

- We accept pre-submission inquiries

- Our selector tool helps you to find the most relevant journal

- We provide round the clock customer support

- Convenient online submission

- Thorough peer review

- Inclusion in PubMed and all major indexing services

- Maximum visibility for your research

Submit your manuscript at www.biomedcentral.com/submit

) Biomed Central 